\title{
Membangun kesehatan mental anak usia dini dengan pengasuhan positif
}

\author{
Dewi Retno Suminar ${ }^{1 *}$; Hamidah ${ }^{2}$ \\ $\left.1^{*}\right), 2$ Universitas Airlangga \\ Jl. Dharmawangsa Dalam selatan 4-6 Surabaya 60286, Indonesia
}

Email: dewi.suminar@psikologi.unair.ac.id; hamidah@psikologi.unair.ac.id

\begin{abstract}
Early childhood who are in PAUD often get developmental stimulation. Apart from providing stimulation, Bunda and Yanda are the closest people to PAUD apart from their parents. Parenting principles are also applied in PAUD. Good parenting at an early age will make children grow up well in the future. A person's mental health problems are often related to early parenting. On this basis, counseling on positive parenting for Bunda and Yanda in early childhood education was carried out. The socialization activities were carried out in Dengok Village, Padangan District, Bojonegoro Regency. Activities carried out to provide solutions to existing parenting problems. Counseling is carried out in two days at intervals of one week to provide opportunities for Bunda and Yanda in PAUD to look for parenting problems in the field so far. The results obtained are quite encouraging because of the increased understanding of Mothers and Yanda in PAUD about positive parenting methods which in turn will make children happier and improve mental health.
\end{abstract}

Kata kunci: Early childhood, positive parenting, mental health

\section{Pendahuluan}

Sejak tahun 2005 lalu pertumbuhan dan perkembangan pos paud terpadu (PPT) mulai dirintis di Kota Surabaya dan pertumbuhannya sangat luar biasa (Katarina, 2016). Program ini kemudian dikembangkan oleh dikmas kota Surabaya dan di Kabupaten di seluruh Jawa Timur dibawah pengelolaan direktorat PLS atau DIKMAS. Pengelola dan pengajar di PPT disebut dengan sebutan "Bunda dan Yanda" PAUD.

Bunda dan Yanda PAUD merupakan pribadi yang memiliki minat untuk membantu pemerintah dalam pengembangan kemampuan anak usia dini. Namun mereka kebanyakan tidak memiliki bekal ilmu yang cukup untuk mengajarkan berbagai pengetahuan dan perilaku kepada anak usia dini, mengingat mereka tidak memiliki latar belakang pendidikan PAUD.

Banyak hal yang dapat dikembangkan pada anak usia dini, salah satunya adalah membangun menyiapkan kesehatan mental anak. Sebab kesehatan mental seseorang seringkali terkait dengan pola pengasuhan yang dialami sejak dini. Pengasuhan mempengaruhi pembentukan karakter dan kepribadian seseorang. Dimana anak menjadi pribadi sehat mental atau justru memiliki kecenderungan gangguan sudah dapat dipahami dan dipetakan dari sejarah pengasuhannya dalam keluarga.

Gangguan kesehatan mental di Jawa Timur khususnya dan di Indonesia umumnya juga meningkat. Sebagaimana ditemukan dari hasil survey RISKESDAS tahun 2018 menunjukkan bahwa terdapat rata-rata 6,1\% remaja berusia lebih 15 tahun mengalami depresi. Angka paling tinggi terdapat di wilayah Sulawesi tengah sebanyak $12,3 \%$ dan paling rendah terdapat 1,8 \% di Jambi. Sedangkan di 
Gorontalo, NTT dan Maluku masih berkisar antara 9-10\% remaja mengalami depresi. Belum lagi gangguan emosi lain.

Berdasarkan pertimbangan tersebut, maka dianggap perlu adanya pembenahan dan perubahan pada pola asuh di keluarganya. Perubahan ini bisa dimulai dengan memberikan pengetahuan dan keterampilan dalam menerapkan pola asuh yang tepat agar anak tumbuh dalam lingkungan hangat dan menjadi pribadi yang kuat dan sehat mental.

Perubahan ini dapat dilakukan dari berbagai sisi, yaitu merombak pengasuhan di sekolah dan dirumah sehingga anak-anak mendapatkan perlakuan dan pengasuhan yang tepat dan konsisten untuk menyiapkan kesehatan mentalnya. Kesehatan mental dapat dibentuk dari kekuatan ego dan kemampuan untuk berfikir positif dan merespon secara positif atas kejadian yang diterimanya dari lingkungan.

Perubahan yang menyeluruh akan terjadi jika dimulai dari masa anak-anak di usia dini dari lingkungan rumah dan sekolah. Oleh sebab itu Bunda PAUD dan orang tua serta kader perlu mendapatkan pelatihan tentang pengasuhan sehat bertujuan untuk membentuk jiwa dan pribadi sehat secara mental. Pengayaan dan peningkatan pengetahuan dan keterampilan mengajarkan kemampuan tersebut kepada orang lain yang berperan sebagai agent of change dalam membangun pengasuhan secara positif dan sehat

Persoalan tersebut perlu diselesaikan agar gangguan kesehatan mental tidak semakin meningkat serta membahayakan dan merugikan orang lain di sekitarnya. Membangun mental sehat sudah mendesak untuk dilakukan sejak awal, mengingat pembentukan kesehatan mental bukanlah hal yang mudah, mengingat banyak perilakuan lingkungan yang tidak memberikan stimulasi dan ruang bagi anak untuk dapat berfikir sehat, mendapatkan perlakuan sehat serta membangun jiwa kuat dan mental sehat.

Permasalahan yang muncul di desa Dengok, kecamatan Padangan Kabupaten Bojonegoro adalah sebagai berikut: (1) Latar belakang pendidikan dan bunda atau yanda PAUD sangat beragam (mulai dari lulusan SMA atau sederajad sampai dengan S-2). (2) Tidak semua bunda PAUD memiliki latar belakang pendidikan atau pelatihan dalam bidang pendidikan PAUD. (3) Banyak lembaga PAUD yang memiliki siswa Inklusi sehingga dibutuhkan kemampuan dan keterampilan yang khusus dalam mengasuhnya. (4) Belum semua Bunda atau Yanda PAUD mendapatkan pelatihan tentang pendidikan PAUD atau PAUD Inklusi. (5)Terdapat anak-anak yang mengalami penyimpangan perkembangan atau perilaku dan juga gangguan kesehatan mental.(6).Belum semua Bunda dan Yanda PAUD mendapatkan pengetahuan, pemahaman dan keterampilan tentang pengasuhan sehat, pengasuhan positif dan pengasuhan Bahagia. (7) Bunda dan Yanda PAUD belum banyak yang memahami bahwa pola asuh memiliki pengaruh terhadap kesehatan mental dan kekuatan pribadi serta gangguan kesehatan mental. (8) Tidak banyak masyarakat yang memiliki kesadaran dan kemauan untuk terlibat dalam memberikan edukasi kepada masyarakat tentang pengasuhan yang berpengaruh terhadap kesehatan mental anak. (9) Masyarakat juga masih banyak yang memberikan pengasuhan untuk membentuk perilaku disiplin dengan menggunakan pendekatan yang kurang tepat.

\section{Literature or conceptual review}

Relasi Bunda dan ayah dengan anak di PAUD merupakan hubungan istimewa karena hampir beberapa hari dampai setiap hari bertemu di sekolah. Anak-anak yang bersekolah di PAUD sedikitnya menghabiskan seperempat waktu dalam sehari di sekolah dan kebanyakan waktu dihabiskan di dalam ruang kelas (Pianta dkk, 2012). Anak-anak juga menghabiskan waktu efektif di sekolah bersama dengan guru dalam hampir semua kegiatan yang dilakukan di sekolah, sehingga segala hal yang dilakukan guru bersama anak di sekolah akan memberikan pengaruh besar terhadap perkembangan anak. 
Hasil penelitian longitudinal yang dilakukan Pianta dan Stuhlman (2004) terhadap anak-anak sejak di prasekolah, TK hingga anak-anak kelas 1 SD pun menunjukkan hasil serupa, bahwa tingkat kedekatan dan konflik dalam relasi guru-anak saling berhubungan. Pianta dan Stuhlman (2004) menjelaskan konflik dalam relasi guru-anak cenderung stabil kemungkinan karena kestabilan karakteristik anak seperti temperamen sedangkan kedekatan dalam relasi guru-anak dipengaruhi oleh hubungan interpersonal antara guru dengan anak. Relasi antara guru dalam hal ini bunda dan yanda adalah sebuah pengasuhan. Pengasuhan sangat erat dalam membentuk mental anak.

Disisi lainnya, Tugas perkembangan usia prasekolah tersebut adalah membangun relasi positif dengan lingkungan sosial, pengelolaan emosi dalam interaksi sosial, tetap terkoneksi dengan orang dewasa sembari bergeser ke dunia teman sebaya, serta ketrampilan belajar seperti berkonsentrasi dan mengikuti arahan guru (Denham dkk., 2016).

Penelitian ini menggunakan perspektif Sistem Bioekologi yang dikembangkan oleh Urie Bronfenbrenner untuk menjelaskan model mental yang sehat anak usia dini. Berdasarkan perspektif Bioekologi, perkembangan mental yang sehat bagi anak tidak dapat dilepaskan dari konteks lingkungannya. Empat komponen utama yang bersifat dinamis dan saling terkait dalam sistem bioekologi, yaitu proses, individu, konteks, dan waktu (model Process-Person-Context-Time atau PPCT). Untuk proses adalah bagaimana kevenderungan yang terjadi relasi antara bundandan yanda di PAUD dengan anak anak. Komponen Individu dapat dilihat dari bagaimana kekhasan anak dan dalam konsisi yang bagaimana. Prinsip individual differences perlu ditrerapkan. Konteks disini perkembangan mental yang sehat bagi anak tertgantu bagaimana pengasuhan khas yang dilakukan didaerah tersebut. Sedangkan konteks waktu dilihat dari micro-time, meso-time, dan macro-time. Micro-time adalah apa yang terjadi selama interaksi atau aktivitas spesifik, yaitu interaksi resiprokal sehari-hari antara orangtua dan anak. Sedangkan meso-time, dan macro-time. tidak menjadi poin dalam aktivitas sekarang.

\section{Metode}

Metode yang akan diterapkan sesuai dengan solusi yang akan ditawarkan dalam pengabdian masayarakat ini agar sejalan dan dapat menghasilkan hasil yang optimal.Berdasarkan permasalahan tersebut diatas, maka solusi yang ditawarkan dalam kegiatan ini adalah sebagai berikut:

1. Memberikan edukasi bukan pelatihan kepada peserta tentang berbagai pola pengasuhan. Pola pengasuhan positif, pengasuhan sehat dan pengasuhan bahagia

2. Memberikan edukasi kepada peserta tentang akibat atau efek dari berbagai pengasuhan terhadap kesehatan mental

3. Memberikan pelatihan tentang bagaimana menerapkan pola pengasuhan secara proporsional untuk dapat membentuk dan membangun kesehatan mental

4. Membangun komunitas yang peduli terhadap pengasuhan yang dapat membangun kesehatan mental

5. Mendorong keterlibatan dan kesadaran masyaralat dalam memberikan pengasuhan yang membangun kesehatan mental

6. Mendorong keterlibatan dan kesadaran masyarakat akan terus ikut menyampaikan dan melanjutkan pengasuhan yang membangun kesehatan mental secara berkelanjutan

7. Membentuk kader dalam pengasuhan sehat

Berdasarkan solusi yang ditawarkan, maka teknologi yang diperlukan adalah sebagai berikut:

1. Edukasi dengan pelatihan dan tanpa pelatihan

2. Buku saku, poster, modul pelatihan, skala alat ukur pengetahuan dan keterampilan tentang pengasuhan yang membentuk kesehatan mental.

3. Metode pelatihan yang digunakan adalah metode yang mengedepankan peran aktif peserta dengan memberikan pendidikan /pembelajaran berdasarkan pengalaman. 
Berdasarkan rencana tersebut, akhirnya peningkatan dan pemberdayaan kemampuan dan kompetensi bunda dan yanda PAUD tentang pengasuhan sehat di PPT desa Dengok kecamatan Padangan Kabupaten Bojonegoro dapat dilakukan dengan strategi psikoedukasi dan Pelatihan. Pelatihan ini dapat dilakukan dengan berbagai metode sesuai dengan tujuan dan aspek kompetensi yang diperlukan.

Metode yang digunakan dalam kegiatan pelatihan dan pendampingan untuk peningkatan kompetensi ini adalah: (1). Ceramah, (2) Diskusi, (3) Roleplay, (4) Presentasi, (5) Games, (6) Permainan (7) Analisis Film dan (8) studi kasus. Rincian dari metode yang digunakan dalam kegiatan ini dijelaskan pada tabel di bawah ini dengan jangka waktu kegiatan 8 bulan.

\section{Hasil dan Pembahasan}

Daerah yang digunakan dalam pelatihan dini adalah di desa Dengok, kecamatan Padangan Kabupaten Bojonegoro. Apabila digambarkan lokasinya adalah sebagai berikut

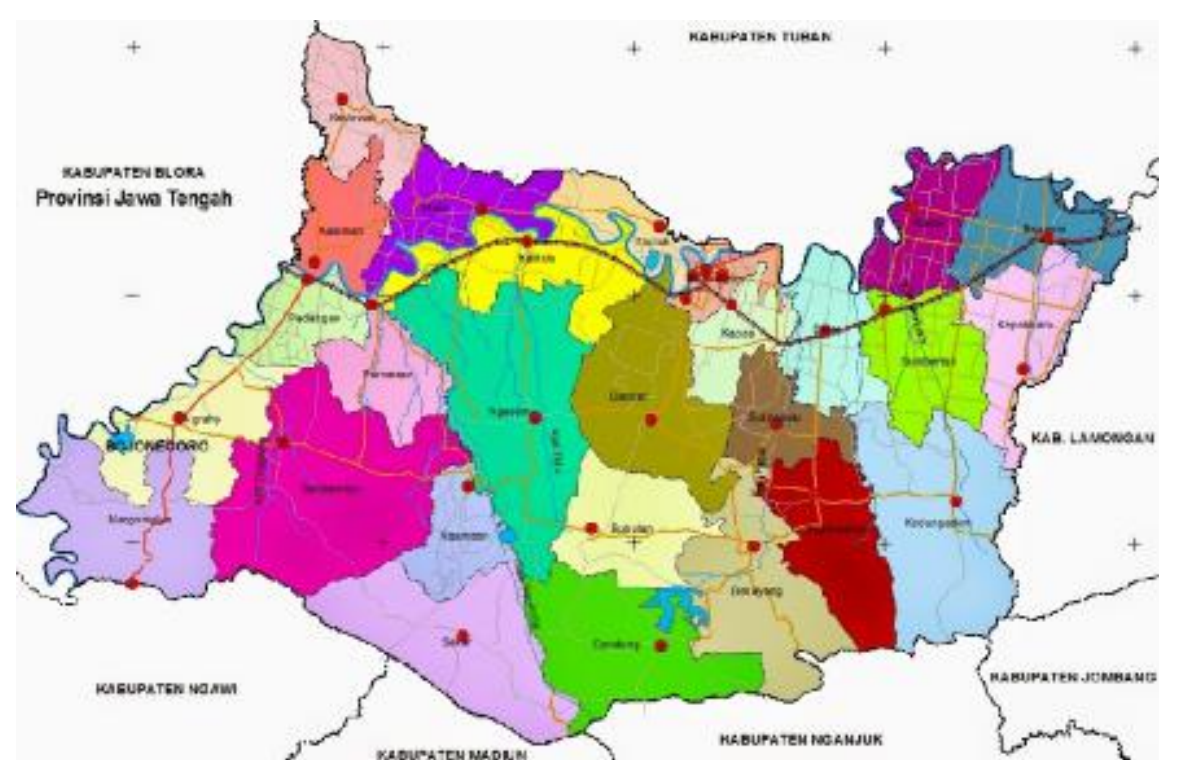

Gambar 1. Peta tempat lokasi kegiatan dilaksanakan

Tempatnya lebih dekat dengan Provinsi Jawa Tengah, dengan area yang masih perlu untuk dikembangkan. Sosialisasi dilakukan dengan menggunakan dua acara Daring dan Luring karena masa pandemi ini. Proses pendampingan dilakukan oleh pemdamping Sarjana Psikologi yang berada di Bojonegoro dengan supervisi penulis. 


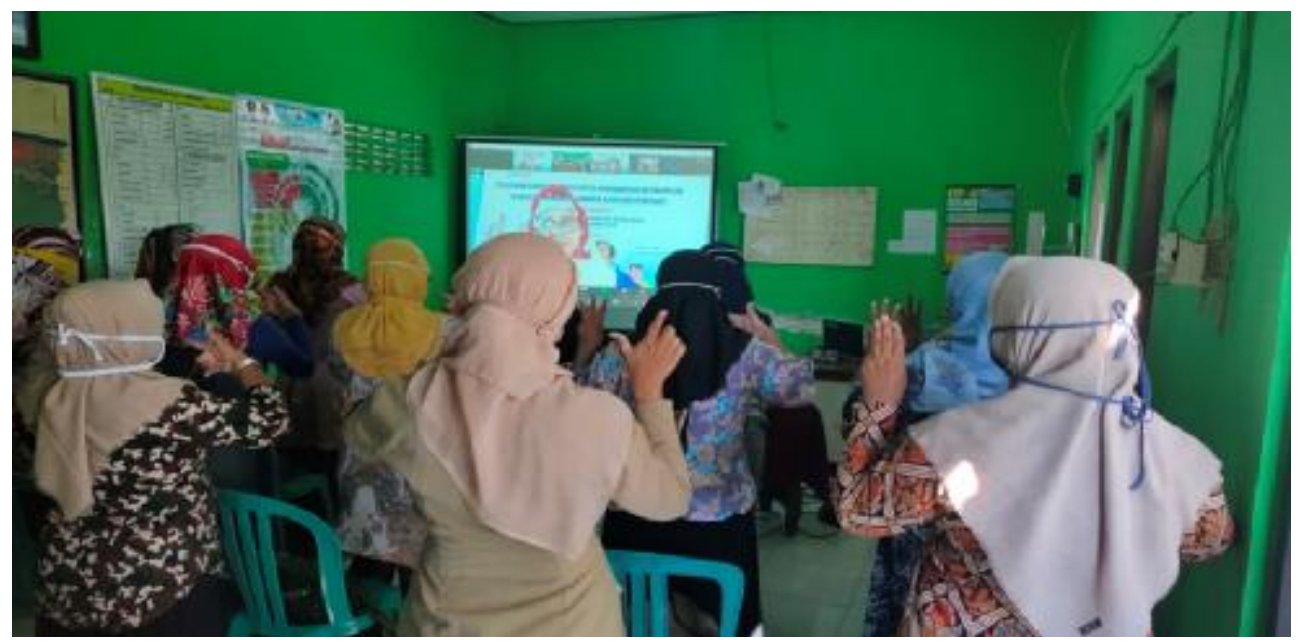

Gambar 2. Suasana tempat penyuluhan

Dari aktivitas kegiatan didapatkan kesepahaman tentang sosialisasi pengasuhan positif dan apa yang dilakukan Ketika terjadi pengasuhan yang tidak positif yang ditengarai dari perilaku yang tidak sehat secara mental. Misalnya anak yang mndaptkan penganiayaan, KDRT dan memperlakukan salah pada anak anak ABK.

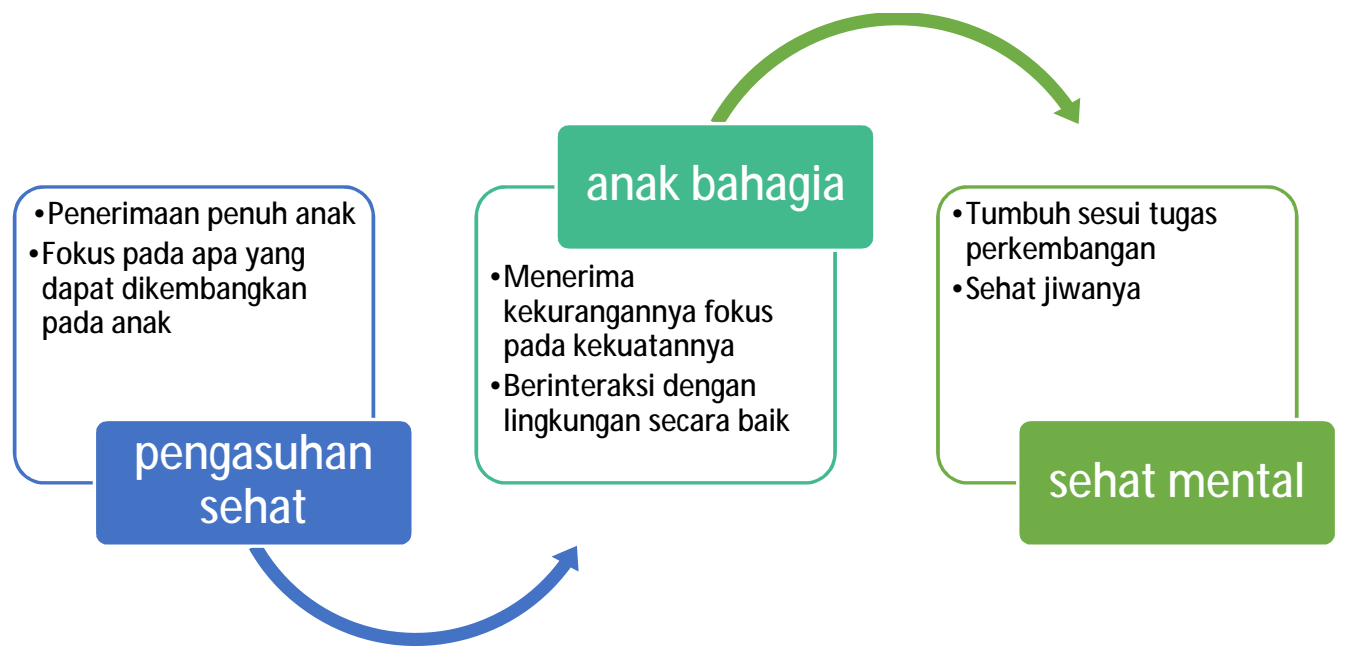

Gambar 3 alur pemahaman bunda dan yanda di PAUD

Berdasarkan gambar 3, maka peserta dapat memberikan pengertian pada orang tua dan juga ketika memainkan peran orang tua sebagai bunda dan yanda di PAUD.

Harapan yang ingin dicapai selain dengan pemahaman yang meningkat dari bunda dan yanda di PAUD, maka yang perlu dilakukan adalah bagaimana membentuk komunitas yang peduli tentang pengasuhan yang positif bagai anak. Pengasuhan yang positif, diharapkan akan dapat membantu para tokoh yang berperan untuk menindak lanjuti ketika adanya pelaporan tentang kekerasan terhadap anak, perlakuan yang salah tentang ABK, Perilaku kekerasan yang dilakukan oleh orang dewasa atau guru. Perlu juga dibuatkan sebuah alur pelaporan dan disisi lain semakin gencar pula terjadinya sosialisasi pengasuhan positif. 


\section{Kesimpulan}

Berdasarkan hasil analisis diatas, maka kesimpulan dari hasil kegiatan ini adalah sebagai berikut: (1) Secara kesekuruhan Terdapat perbedaan pengaruh yang signifikan antara pre dan post test pelatihan pengasuhan positif untuk meningkatkan pengetahuan dan keterampilan, (2). Berdasarkan pendidikan, pelatihan ini memiliki perbedaan pengaruh lebih kuat pada Bunda PAUD dengan berpendidikan S1 dibanding SMA, (3). Terdapat perbedaan pengaruh lebih tinggi pada BUNDA PAUD yang berusia dewasa Madya bila dibanding dengan usia dewasa awal

Berdasarkan hasil dan kesimpulan dari penelitian ini, maka dapat dituliskan saran: (1). Saran bagi bunda PAUD, dianjurkan untuk dapat menerapkan dan mensosialisasikan pengetahuan dan keterampilan tentang pengasuhan positif yang telah diperoleh selama pelatihan ini kepada orang tua siswa, kader, keluarga dan masyarakat untuk dapat menerapkan pola pengasuhan positif pada anak untuk membangun karakter tangguh melalui pribadi yang sehat dan cerdas ,(2). Saran bagi keluarga / orang tua seyogyanya melakukan pembelajaran melalui diskusi atau konsultasi dengan bunda PAUD atau professional tentang pengasuhan positif yang tepat pada anak agar anak dapat tumbuh dan berkembang menjadi pribadi yang tangguh dan sehat, (3).Saran bagi pengelola PPT dianjurkan untuk secara periodik mengadakan refreshing materi pelatihan pengasuhan positif pada bunda PAUD untuk menguatkan dan mengembangkan pengetahuan dan keterampilan yang sudah didapatkan ketika pelatihan

\section{Ucapan Terimakasih}

Kepala desa Desa Dengok Kecamatan Padangan Kabupaten Bojonegoro, Bapak Supriyanto atas bantuannya dalam mengkoordinasi poeserta dan juga penyediaan tempat kegiatan

\section{Daftar Pustaka}

Asbari, M., Nurhayati, W., Purwanto, A. (2019). Pengaruh Parenting Style dan Personality

Genetic terhadap pengembangan Karakter Anak di PAUD Islamic School, JURNAL AUDI: Jurnal Ilmiah Kajian Ilmu Anak dan Media Informasi PAUD. Vol 4 no 2. DOI: http://dx.doi.org/10.33061/hai.v4i2.3344

Bronfenbrenner, U. \& Morris, P. A. (2006). The bioecological model of human development. Dalam R.M. Lerner \& W. Damon (eds.). Handbook of Child Psychology. Volume I. Theoretical Models of Human Development. New Jersey: John Wiley \& Sons., p.793-828.

Denham, S. A., Ferrier, D. E., Howarth, G. Z., Herndon, K. J., \& Bassett, H. H. (2016). Key considerations in assessing young children's emotional competence. Cambridge Journal of Education, 46(3), $299-317$. https://doi.org/10.1080/0305764X.2016.1146659

Hawi, A., Afnibar, S. N. U., Syaifulloh, M., \& Mukhlis, H. (2020). Emotional and Social Character Development during Growth Period. Journal of Critical Reviews, 7(8), 2013-2018.

Hurley KD, Huscroft-D'Angelo J, Trout A, Griffith A, Epstein M.(2014), Assessing parenting skills and attitudes: A review of the psychometrics of parenting measures. Journal of Child and Family Studies.;23(5):812-823.

Katarina. D. (2016), Motivasi Bunda PAUD di Pos Paud Terpadu Wilayah Surabaya, Tesis, Fakultas 
Psikologi Universitas Airlangga, tidak diterbitkan.

Kementrian Pendidikan dan Kebudayaan Direktorat Jendral Pendidikan Anak Usia Dini dan Pendidikan Masyarakat Direktorat Pendidikan dan Pembinaan Keluarga. (2017). Pengasuhan Positif., Jakarta. E-book. https://sahabatkeluarga.lemendikbud.go.id

Locke, L. M., \& Prinz, R. J. (2002). Measurement of parental discipline and nurturance. Clinical psychology review, 22(6), 895-929. https://doi.org/10.1016/s0272-7358(02)00133-2

Pianta, R. C. (2001). Student-Teacher Relationship Scale: Professional manual. Odessa,FL: Psychological Assessment Resources,Inc.

Pianta, R.C. \& Stuhlman, M. W. (2004). Teacher-child relationships and children's success in the first years of school. School Psychology Review, 33(3), $444-458$

Ramey SL. (2016), The science and art of parenting. In: Borkowski JG, Ramey SL, Bristol-Power M, editors. Parenting and the child's world: Influences on academic, intellectual, and social-emotional development. Lawrence Erlbaum Associates Publishers; Mahwah, NJ: 2016. pp. 47-74. [Google Scholar]

Rohayati, T. (2016). Pengembangan Perilaku Sosial Pada Anak Usia Dini. Artikel Imiha,n Univeristas Persada Indonesia, Jakarta.

Suryani, Y., Palupi, R., \& Kusuma, A. (2020). Pendekatan modelling keperawatan anak pada orang tua dalam menstimulasi anak usia dini dengan masalah perubahan perilaku dengan kebiasaan menggunakan gadget. Majalah Kesehatan Indonesia, $1(1), \quad 1$ - 6. doi:https://doi.org/10.47679/makein.011.62000001

Tinsley, B. J., Markey, C. N., Ericksen, A. J., Kwasman, A., Ortiz, R.V. (2002\}. Health Promotion for Parents. Handbook of Parenting), Volume 5, Pratical issue in parenting. Edited by Marc H. Bornstein, New Jersey: Lawrence Erlbaum Associates, Publisher.

Triaristina, A., \& Mukhlis, H. (2019). Implemetasi Pendidikan Karakter Melalui Media Dongeng Berbasis Visual Pada Anak Usia 4-6 Tahun. Journal of Psychological Perspective, 1(1), 35-40.

Yati, P. (2016). Pendidikan Karakter Anak Usia Dini Melalui Metode Pembelajaran Field Trip. Lentera, 18(1). 123. 
